\title{
Intervenciones de comunicación exitosas para el cuidado a la salud en personas con deficiencia auditiva
}

\section{Successful communication health care interventions on persons with auditory impairments}

PSS L.E.O Nydia Loredo Martínez

Mtra. Reyna Matus Miranda.

\section{Resumen}

Las personas con deficiencias auditivas suman hoy en día una población, cada vez más grande dentro de nuestro país. Forman un grupo con características y necesidades propias de una cultura en particular. Utilizan diferentes formas de comunicación para una inserción oportuna en los diferentes ámbitos socioculturales dentro de una sociedad oyente con la cual comparten las mismas inquietudes y necesidades.

A partir de la experiencia hospitalaria se ve la necesidad de la búsqueda de intervenciones de comunicación exitosas durante el cuidado a personas con deficiencias auditivas por el personal de salud para establecer un diagnóstico y plan de cuidados oportunos que respondan a las necesidades surgidas durante el proceso salud-enfermedad.

La pregunta que guió esta revisión de la literatura fue ¿Cuáles son las intervenciones de comunicación para el cuidado a la salud en personas con deficiencia auditiva que existen en la literatura de enfermería en el periodo 2000-2012? Se consultaron las bases de datos PubMed, Scielo, Index, Redalyc, Cuiden plus, Cuiden Evidentia y Lilacs con las siguientes palabras clave en español e inglés: Pacientes sordomudos, Sordera, Deficiencia auditiva, lenguaje de señas, Comunicación, Educación, Cuidado, Salud, Enfermería. Se identificó un total de 437 artículos, estos fueron depurados de acuerdo a los criterios de inclusión y se obtuvo un total de 17 artículos útiles.

Los resultados de esta revisión confirman que la comunicación no verbal en su modalidad de lenguaje de señas, materiales visuales y el uso de intérpretes; resultan exitosos durante el cuidado para el establecimiento del proceso comunicativo ya que forman parte de un sistema lingüístico propio y oficialmente reconocido como parte de una cultura sorda.

-Profesora de Carrera TC Asociado ENEO UNAM

FECHA DE RECIBIDO: 29 DE JUNIO 2012

Fecha de ENVIAdo: 6 DE JUlio 2012

FeCha de ACEPTAdo: 31 DE Agosto 2012 


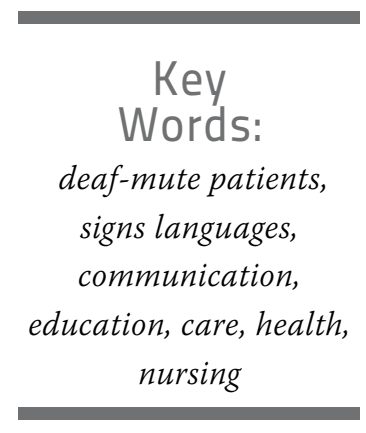

ABSTRAC

People suffering from auditory impairments are an everyday larger population with unique characteristics, needs, and culture. These persons have to use specific communication protocols to become part of a hearing society, in which they also share the same expectations and needs.

It is necessary to design successful communication interventions on persons with auditory impairments in order to establish adequate care plans which can timely address their health-illness process needs.

The question guiding this literature review was: Which were the healthcare communication interventions on persons with auditory impairments between the year 2000 and 2012? PubMed, Scielo, Index, Redalyc, Cuiden plus, Cuiden Evidentia and Lilacs databases were consulted with the following key words in English and Spanish: deaf-mute patients, deafness, auditory impairment, sign-languages, communication, education, care, health, nursing. A total of 437 articles were identified, and after inclusion criteria were applied, 17 final articles were kept.

Outcomes of this review confirm that non-verbal communication in its sign language form, visual aids, and the use of interpreters, are all useful and culturally acknowledged during the care process in people suffering from auditory impairments.

\section{INTRODUCCIÓN}

La comunicación es la base para el desarrollo físico, psicológico, social y cultural de todo ser humano; nace como una acción vital al socializar y formar grupos que comparten ideas y características socioculturales con la cual se identifican. ${ }^{1}$ Ésta es una habilidad que refleja la capacidad del hombre para simbolizar lo que observa y siente del entorno que lo rodea, a través de un lenguaje.

Por su parte la lengua es un conjunto de códigos o señas relacionados entre sí que sirven para conformar los mensajes lingüísticos; pudiéndose expresar de manera verbal y no verbal, ${ }^{2}$ como pueden ser movimientos, sonidos, imágenes o bien objetos que son usados para transmitir ideas. Esto en su conjunto forma un lenguaje en específico que reproduce patrones de pensamiento y experiencias complejas en un tiempo y espacio determinado.
Los elementos que determinan la comunicación son: él emisor (con una intención), un mensaje, un receptor, un referente (el tema del que se habla), un canal de comunicación (la escritura, la imagen, el sonido) y un código de expresión (la lengua, el canto, la pintura, la fotografía). ${ }^{2}$

El conocimiento de los códigos de expresión ayudan al entendimiento correcto del mensaje transmitido, de la misma forma la elección idónea de un canal de comunicación garantiza un lazo de confianza entre el emisor y el receptor, lo contrario puede provocar en las personas conductas de miedo, frustración, apatía o retraimiento social. ${ }^{3}$

Aunado a lo anterior para una comunicación exitosa se debe propiciar un ambiente neutral sin distractores que facilite la transmisión de la información y que pueda ser modificable de acuerdo a la situación y necesidades de cada perso$\mathrm{na}^{4}$ (espacios físicos amplios y cerrados, iluminación, ubicación de inmobiliario, uso de utilería etc.), todo esto en conjunto determinará que el receptor comprenda, maneje y reproduzca la información que el emisor haya transmitido y a la inversa él emisor también lo haga. ${ }^{5}$

Es importante señalar que existen diversas formas de comunicación dependiendo de cada persona, de sus características socioculturales y físicas e incluso con algún tipo de discapacidad (una o más deficiencias físicas, mentales, intelectuales o sensoriales) y que al interactuar con distintos ambientes del entorno social pueden impedir su participación plena y efectiva en igualdad de condiciones a los demás. ${ }^{6}$

En nuestro país, el número de habitantes con algún tipo de disca- 
pacidad para el año 2010 de acuerdo con el Instituto Nacional de Estadística y Geografía (INEGI), fue de 5 millones 739 mil 270. ${ }^{6}$ Dentro del Distrito Federal las limitaciones físicas más comunes son: para caminar y moverse, para ver, con deficiencias mentales, para hablar o comunicarse, para poner atención o aprender, para proporcionarse autocuidado y las auditivas.

Esta última en particular representa el motivo de este artículo de revisión; ya que de alguna manera es un reto para enfermería al momento de establecer comunicación y obtener información personal del paciente que le ayude a la satisfacción de sus necesidades durante el proceso salud-enfermedad. Así este artículo tiene como población blanco aquellas personas con deficiencias auditivas ya que se hace implícito el uso de diferentes formas de comunicación no verbal.

El termino deficiencias auditivas es sinónimo de sordera, en este grupo se incluye a las personas que no pueden oír, así como aquellas que presentan dificultad para escuchar (debilidad auditiva), en uno o ambos oídos sea por nacimiento o porque la adquirió después de haber aprendido el lenguaje oral y que aún usando un aparato auditivo presentan dificultad para escuchar debido a lo avanzado de su problema. ${ }^{6}$

Las personas con deficiencias auditivas o sordas desarrollan sus propias características que a su vez modulan sus valores, creencias, formas de recreación, aprendizaje y movilización; así constituyen grupos con formas de vida cultural propia; ${ }^{7}$ la orientación que reciben para interactuar socialmente está determinada por su núcleo fami-
Las personas con

deficiencias auditivas

o sordas desarrollan sus propias

características que a su vez modulan sus valores,

creencias, formas de recreación, aprendizaje y movilización; así constituyen grupos con formas de vida cultural propia.

liar, la edad y la educación formal recibida que genera en ellos las capacidades y habilidades necesarias para la comunicación oral (lectura facial y labial) y la adquisición del lenguaje de señas como lengua mater. Lo anterior propicia el desarrollo de una cultura particular de comunicación no verbal, ${ }^{8}$ dentro una sociedad donde prevalece la comunicación verbal.

Para establecer comunicación ésta población de acuerdo con la Ley General para la inclusión de personas con discapacidades, se debe considerar las siguientes formas de lenguaje: escrito, oral y la lengua de señas mexicana, la visualización de textos, la comunicación táctil, los macro tipos, los dispositivos multimedia escritos de fácil acceso, el lenguaje sencillo, medios, sistemas y formatos aumentativos o alternativos de comunicación incluida la tecnología de la información y comunicaciones de fácil acceso. $^{1}$

Comúnmente las personas con deficiencias auditivas al establecer comunicación con personas oyen- tes hacen uso de otras estrategias de comunicación no verbales, lo que puede representar un problema; ya que se enfrentan a una sociedad que desconoce el lenguaje de señas como un idioma primario mundialmente reconocido.

El lenguaje de señas se define como un sistema lingüístico o una variante del mismo que implica el uso de gestos, ademanes, señales, movimientos del cuerpo, manos y rostro para declarar, explicar o dar a entender lo que uno piensa o quiere. Tiene características singulares ya que cada país o grupo étnico tiene sus propias señas o modismos; es decir su propia lengua distintiva que proviene de las características socio culturales de cada región usada para la trasmisión de costumbres de generación en generación, modificada de acuerdo con el tiempo, forma parte de un sistema aumentado y reorganizado con el fin de adaptarlo a sus necesidades, su realidad cultural y tecnológica. Es un lenguaje flexible con la habilidad de indicar múltiples personas, números, tiempos, afirmaciones $y$ preguntas, tal como es posible en el lenguaje verbal., 8

De esta manera, y dado el número de personas con alguna limitación auditiva, se vuelve una necesidad preponderante pensar en acciones que permitan la comunicación con ellas durante el encuentro con los profesionales de servicios de salud, en donde enfermería sin duda tiene un amplio escenario de trabajo. Es un hecho que los profesionales de la salud y del cuidado deben conocer y considerar las características socioculturales que definen a estos grupos sociales como una parte importante para hacerlos sentir como personas 
y no como un enfermo o patología ${ }^{9}$ y cultivar en ellos sentimientos de pertenencia.

Las personas que cuentan con limitaciones para la comunicación (sordos, mudos, débiles visuales o auditivos, ciegos) llevan siempre implícito un riesgo adicional al no poder identificarse, no tener un acceso total a la sociedad que los rodea y a los diferentes servicios que por ley les corresponde; como la educación y salud, ${ }^{10}$ de la misma manera al depender de terceras personas para poder incluirse en algún rol social

En la experiencia personal se ha observado que el personal al no poderse comunicar con personas con sordera que ingresan a un servicio de salud, los "ignora", ya que la comunicación, o mejor dicho los intentos de ello, pueden ser estresantes para ambas partes con el consecuente costo para el cuidado. En estos casos la comunicación ocurre solo cuando se cuenta con la presencia de un familiar de la persona que funge como "traductor"; con el riesgo de la omisión de información del paciente a los familiares y por consecuencia al profesional de la salud y del cuidado. ${ }^{11}$ Es importante considerar que durante el proceso de traducción siempre está implícito un "error" en la interpretación o sentido de lo dicho, sin embargo siempre será mejor que "cuidar en el silencio".

Derivado a lo anterior es pertinente exponer algunas de las estrategias exitosas que el profesional del cuidado podría considerar para optimizar sus intervenciones en personas con limitaciones o deficiencias auditivas y hacer valer el derecho de estas a una atención sanitaria personal, eficaz, y espe-
Las personas que cuentan con limitaciones para la comunicación llevan siempre implícito un riesgo adicional al no poder identificarse, no tener un acceso total a la sociedad que los rodea y a los diferentes servicios que por ley les corresponde; como la educación y salud, de la misma manera al depender de terceras personas para poder incluirse en algún rol social

cifica que responda a sus necesidades. ${ }^{11,12,13}$

Dado que la falta de capacitación del personal para afrontar situaciones diferentes de comunicación se constituye en una barrera para la planeación y ejecución de los cuidados de enfermería esto puede prolongar la estancia, los costos hospitalarios y de la misma forma resultar en un desgaste emocional ${ }^{3}$ para la persona con deficiencia auditiva, sus familiares y del propio personal de salud al no saber cómo comunicarse y cómo darse a entender; pues de acuerdo a algunos estudios en el tema el profesional de enfermería no tiene considerado dentro de su formación profesional o laboral estrategias de comunicación diferente a la verbal, y solo una minoría al tener contacto con personas sordas busca formas de establecer comunicación de acuerdo a su necesidad de ser comprendidos. . $^{13,14}$

Una parte elemental en el cuidado, es el conocimiento de los factores que intervienen en éste (biológicos, fisiológicos, socioculturales y espirituales) y que se ven reflejados en el propio autocuidado de la persona; recolectados por medio de la entrevista y la valoración inicial al paciente ${ }^{8}$ así como de las pruebas diagnósticas de gabinete y laboratorio. ${ }^{15}$ No obstante para brindar tratamiento y cuidados adecuados, en los aspectos técnicos y humanos, se hace necesario conocer cómo se da el proceso de comunicación en el acto de cuidar y ser cuidado. ${ }^{14}$

Este documento se centra en las estrategias de comunicación utilizadas durante el cuidado en personas con deficiencias auditivas en el primer y segundo nivel de atención, se espera que sirvan de referente a aquellos interesados en este espacio del cuidado.

Por lo anterior se planteó la siguiente pregunta: ¿Cuáles son las intervenciones de comunicación para el cuidado a la salud en personas con deficiencia auditiva que existen en la literatura de enfermería en el periodo 2000-2012?

\section{Metodología}

Se buscaron palabras claves provenientes de Descriptores de Ciencias de la Salud (DeCS) y términos Mesh de la página Web de la Biblioteca Virtual en Salud (BVs) y PubMed; se obtuvieron las siguientes en español e inglés: Pacientes sordomudos-Deaf patients; SorderaDeafness-Dumb; Deficiencia auditiva-Deaf-Hearing Loss; Lenguaje de señas- Signs Language; Comunicación-Communication; EducaciónEducation; Cuidado-Caring/ Care; Salud- Health; Enfermerìa-Nursing.

Con las cuales se formaron las siguientes estrategias de búsqueda: Caring AND Deaf Not Otitis; Len- 
guaje de Señas AND Deficiencia Auditiva; Deficiencia Auditiva AND Cuidado; Sordos AND Enfermería AND Comunicación; Sordera AND Comunicación AND Cuidado; Deficiencia Auditiva AND Sordera AND Enfermería; Sordera AND Cuidados AND Enfermería; Educación AND Salud And Sordos; Hearing Loss AND Nursing Care AND Communicating; Deafness OR Dumb AND Nursing Care; Deaf AND Sign Language And Nursing Care.

Establecidas estas estrategias se procedió a introducirlas dentro de las bases de datos PubMed, Scielo, Index, Redalyc, Cuiden plus, Cuiden Evidentia y Lilacs.

Inicialmente se obtuvo una muestra correspondiente a 437 artículos; los cuales fueron revisados de acuerdo a los siguientes criterios de inclusión:

- Acceso a las publicaciones a través de internet o impresas.

- Artículos de enfermería sobre comunicación y estrategias para personas sordas durante el cuidado.

- Periodo dentro del $2000 \mathrm{al}$ primer trimestre del 2012.

- Artículos de revisión, investigación cualitativa, estudios de casos y controles e innovación para la práctica.

- Rango de edad de 19 a más años.

Basado en lo anterior se excluyeron a 420 artículos; por ser artículos de narración de experiencias al tener contacto con personas con sordera, de opinión o de otras disciplinas. Con lo que se redujo la muestra a un total de 17 artículos útiles, éstos artículos son de revistas de enfermería de circulación electrónica publicados desde el año 2000 al primer trimestre del año 2012, de países como Brasil, España, México y Estados Unidos de América (E.U.A); también se recurrió al repositorio de revistas electrónicas de la Dirección General de Bibliotecas de la Universidad Nacional Autónoma de México (UNAM) para la localización de los artículos obtenidos a través de las bases mencionadas.

Previo al análisis se construyó una tabla para la comparación de la metodología, resultados y discusión. Se identificaron principalmente las estrategias de comunicación exitosas y las no exitosas durante el cuidado.

La revisión de los artículos se realizó dentro de un periodo de 4 meses, revisados dos veces; una antes de la traducción y después de ser traducidos para cotejar la congruencia de las ideas, antes de ser vaciados en tablas de comparación para disminuir los errores al interpretar la información; lo anterior se realizó previa lectura completa de los artículos. El análisis de los resultados se realizó mediante estadística descriptiva.

\section{Resultados}

Los artículos publicados durante el año 2000 al 2012 identificados a partir de las palabras claves y estrategias de búsqueda utilizadas se distribuyeron en las bases de datos de la manera siguiente: Redalyc (94),Índex-Cuiden Plus (28), Cuiden Evidentia (1), Pubmed (239), Scielo (55), Lilacs (20). Constituyen un total de 437 artículos, los cuales fueron depurados de acuerdo a los criterios de inclusión y exclusión para dar un total de 17 artículos útiles dentro de los criterios.
El idioma de mayor prevalencia es el inglés con un 53\%, portugués con un $24 \%$ al igual que el español. Dichos artículos proceden de Brasil 41\%, E.U.A 29\%, España 24\% e Inglaterra con un $6 \%$ respectivamente.

Según los estudios consultados Brasil ha revisado e implementado programas con estrategias de comunicación exitosas para personas con deficiencias auditivas ya que en los últimos años se ha visto un aumento en la población con deficiencias auditivas en este país. ${ }^{5,11,}$ 12,16

Los principales diseños de estudio abordados muestran una tendencia cualitativa con $47 \%$ de incidencia, orientados a exponer la experiencia de las personas con deficiencias auditivas dentro de un hospital y de la misma forma del personal sanitario al no contar con los conocimientos y herramientas necesarios para interactuar con este tipo de población; solo un $6 \%$, de los estudios tiene un enfoque cuantitativo enfocados al establecimiento de programas piloto con estrategias de comunicación dirigidos al personal de salud.

Un 24\% son artículos de Revisión bibliográfica los cuales exponen la necesidad de incluir en la formación del personal de salud la enseñanza del leguaje de señas, la carencia de intérpretes oficiales y traductores dentro del espacio hospitalario, cuyo objetivo es dar a conocer al personal de salud estrategias de comunicación aptas de acuerdo al estudio de sus posibilidades laborales dentro de un espacio hospitalario.

Según los estudios en el tema, la implementación de programas de educación prevalece en un $24 \%$ en 
donde proponen técnicas de enseñanza a personas con deficiencias auditivas lo que resulta eficaz al usar el lenguaje de señas (por medio de intérpretes oficiales) combinado con técnicas visuales como imágenes y videos.

Durante el análisis de los artículos se encontraron las siguientes intervenciones de comunicación exitosas para el cuidado a la salud de personas con deficiencias audi- tivas, es importante mencionar que algunos autores mencionan varias estrategias útiles en sus resultados, y no solo una en especifico, por lo tanto se tomó en cuenta una frecuencia de mención por articulo dando a entender que el mayor porcentaje es la estrategia de comunicación más exitosa, obteniendo los siguientes tres resultados principales: a) Lenguaje de señas oficial $b$ ) Uso de materiales visua- les en forma escrita, en imágenes y video y, Uso de intérpretes oficiales (Véase tabla 1)

Por otra parte las tres principales estrategias que no son exitosas durante el cuidado por frecuencia de mención en los artículos revisados fueron las siguientes: Lenguaje verbal, Lectura facial y labial y, Familiares como interpretes y lenguaje de señas (Véase tabla 2):

\section{Tabla. 1 Estrategias exitosas}

\begin{tabular}{|l|c|c|c|}
\hline \multicolumn{1}{|l|}{ Estrategias exitosas } & 12 & 70.59 & 0.40 \\
\hline Lenguaje de señas. & 8 & 47.06 & 0.27 \\
\hline $\begin{array}{l}\text { Materiales visuales en forma escrita y en imáge- } \\
\text { nes. }\end{array}$ & 7 & 41.18 & 0.23 \\
\hline Intérpretes oficiales. & 1 & 5.88 & 0.03 \\
\hline Percusión de objetos cercanos. & 1 & 5.88 & 0.03 \\
\hline Comunicación verbal. & 1 & 4.15 & 0.03 \\
\hline Familiares como intérpretes. & & & \\
\hline
\end{tabular}

\section{Tabla. 2 Estrategias No exitosas}

\begin{tabular}{|l|c|c|c|}
\hline \multicolumn{2}{|c|}{ Frecuencia } & Media \\
\hline Lenguaje verbal. & 16 & 94.12 & 0.47 \\
\hline Lectura labial y facial. & 5 & 29.41 & 0.15 \\
\hline Familiares como intérpretes. & 4 & 23.53 & 0.12 \\
\hline Lenguaje escrito. & 3 & 17.65 & 0.09 \\
\hline Lenguaje de señas. & 2 & 11.76 & 0.06 \\
\hline Intérpretes oficiales. & 2 & 11.76 & 0.06 \\
\hline Gestos. & 1 & 5.88 & 0.03 \\
\hline Didactología. & 1 & 5.88 & 0.03 \\
\hline
\end{tabular}




\section{Tabla 3. Estrategias de comunicación exitosas durante el cuidado a personas con deficiencias auditivas}

\begin{tabular}{|c|c|}
\hline $\begin{array}{l}\text { Estrategias } \\
\text { exitosas }\end{array}$ & Descripción \\
\hline 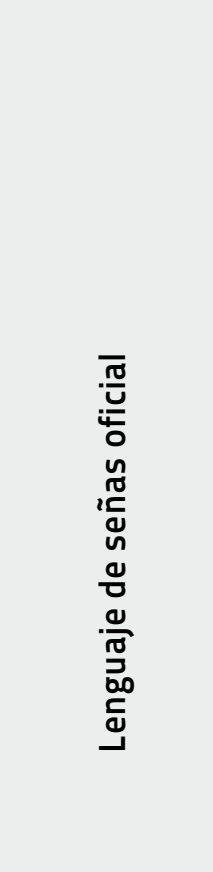 & $\begin{array}{l}\text { Lengua de una comunidad de sordos, que consis- } \\
\text { te en una serie de señas gestuales articulados con } \\
\text { las manos y acompañados de expresiones faciales, } \\
\text { mirada intencional, y movimiento corporal dotado } \\
\text { de función lingüística, forma parte de un patrimo- } \\
\text { nio lingüístico de dicha comunidad. }{ }^{1} \\
\text { Posee una gramática propia y diferente de } \\
\text { la lengua verbal. } \\
\text { Se deben tomar en cuenta las siguientes sugeren- } \\
\text { cias para establecer comunicación a través del } \\
\text { lenguaje de señas: } \\
\text { No interponerse entre las personas que están con- } \\
\text { versando, ya que se interrumpe la comunicación o } \\
\text { se pierde el contacto con los objetos. } \\
\text { La dirección de la mirada y mantener el contacto } \\
\text { visual garantizan la transmisión eficaz } \\
\text { de información hacia la persona sorda, } \\
\text { En el lenguaje de señas se acepta señalar personas } \\
\text { y objetos. }\end{array}$ \\
\hline
\end{tabular}

Tipo de comunicación utilizada

Ventajas

El lenguaje de señas es la lengua primaria de las comunidades de personas sordas.

Su dominio facilita la comunicación como cualquier otra lengua.

Disminuye el estrés generado entre el personal de salud y la persona sorda.

Crea sentimientos de pertenencia a una cultura propia. Disminuye el tiempo y estancia dentro de los espacios hospitalarios al facilitar la consecución de información y garantizar el entendimiento de información e indicaciones del personal de salud.

Se garantiza el acceso, inclusión, convivencia y participación en igualdad de oportunidades al sistema de salud con el resto de la población.

Mantener una distancia de un metro permite la visualización del torso superior del cuerpo y las manos.

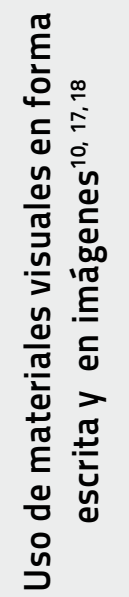

Propone tablas de lenguaje de señas.

Pictografías del Alfabeto con una sola mano.

Lista de preguntas comunes redactadas

de manera sencilla y en tercera persona

con opciones de respuesta "Si" y "No".

Materiales visuales de apoyo dependiendo el tema como: maniquís anatómicos, kit de instrumentos, medicamentos, anticonceptivos, equipó medico etc.

Folletos para la educación a la salud para sordos en lenguaje oficial validados por un grupo de expertos en comunicación con personas sordas. ${ }^{17}$ Actividades lúdicas movilizan los sentimientos y las emociones también representa un sistema de intercambio cultural.

El material debe ser elaborado específicamente a las necesidades propias de la persona sorda, esto quiere decir que se debe conocer y valorar con tiempo a la persona a la que va dirigido.
Permite a las personas sordas identificar las leras, consonantes y palabras.

Ayuda a establecer asociaciones de imágenes, señales y símbolos establecidas que ayuden a identificar acciones, procesos, técnicas, estudios y situaciones tales como las que indican peligro, rutas de evacuación, emergencia, zonas de no fumar, rutas de evacuación, baños, secciones del hospital, zonas para comer, casetas telefónicas, vías y formas de ministración de medicamentos, etc.

Uso de colores ayuda a captar la atención de la persona y a resaltar lo importante.

El uso de materiales visuales facilita la transmisión de información de manera sencilla y clara.

Es una forma de transmitir información e indicaciones fácil, rápida y reutilizable si se elabora bien Son de fácil elaboración y de bajo costo.

Se ajusta a las habilidades y condiciones laborales del personal de salud 


\begin{tabular}{|c|c|c|}
\hline 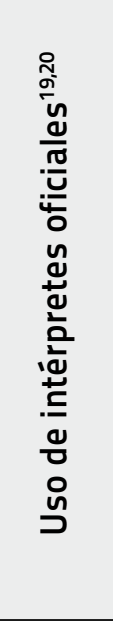 & $\begin{array}{l}\text { Estos deben de tener experiencia en el manejo } \\
\text { de la terminología médica y en la interpretación } \\
\text { de una forma sencilla y entendible al lenguaje de } \\
\text { señas, sin salir del contexto medico. }{ }^{19} \\
\text { La presencia del intérprete debe estas mediada } \\
\text { bajo el derecho de confidencialidad y no emisión } \\
\text { de juicios. }{ }^{20} \\
\text { Se debe de explicar al paciente la presencia del } \\
\text { intérprete y sobre todo los aspectos de la consulta, } \\
\text { pasos a seguir y procedimientos; es recomendable } \\
\text { hacerlo también en forma escrita. } \\
\text { De esta forma se les estará cubriendo su derecho a } \\
\text { recibir asistencia lingüística. }{ }^{19} \text { Lo más importante } \\
\text { es confirmar que el paciente esté entendiendo } \\
\text { la información e indicaciones de diagnóstico, } \\
\text { cuidado y tratamiento. }\end{array}$ & $\begin{array}{l}\text { Facilita la consecución de datos importantes sobre } \\
\text { la salud de la persona sorda. } \\
\text { Reduce los tiempos de estancia de la persona en consulta y hos- } \\
\text { pitalización al tener la información y explicación oportuna, } \\
\text { al conocer a tiempo las necesidades de la persona sorda, se } \\
\text { ofrece un cuidado eficaz y con calidad. } \\
\text { Evita mal entendidos y omisiones en la traducción } \\
\text { de información persona-profesional de salud } \\
\text { El uso de intérpretes oficiales facilita el establecimiento } \\
\text { de confianza entre la persona sorda y el profesional de salud, } \\
\text { al ayudar a presentar, explicar los diagnósticos, tratamientos, } \\
\text { equipo, materiales, etc. } \\
\text { El intérprete aprende a identificar la semiología médica. }\end{array}$ \\
\hline 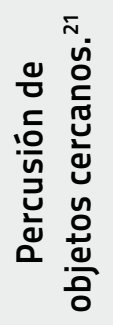 & $\begin{array}{l}\text { Consiste en golpear una superficie cercana a la } \\
\text { persona sorda con otro objeto solido con el obje- } \\
\text { tivo de llamar su atención por medio de las vibra- } \\
\text { ciones transmitidas del objeto hacia él, originadas } \\
\text { al golpear un objeto con otro. }\end{array}$ & $\begin{array}{l}\text { Esta estrategia es usada para captar la atención de la persona } \\
\text { sorda y conseguir el contacto visual de la misma, para indicar } \\
\text { turnos, que se cambie de lugar o posición. También funciona } \\
\text { como un indicativo de las cosas, objetos o presencia del perso- } \\
\text { nal. }\end{array}$ \\
\hline
\end{tabular}

\section{Tabla 4. Estrategias de comunicación No exitosas durante el cuidado a personas con deficiencias auditivas}

\begin{tabular}{|c|c|c|}
\hline Estrategias No exitosas & $\begin{array}{l}\text { Tipo de comunicación } \\
\text { utilizada }\end{array}$ & Desventajas \\
\hline \multirow{2}{*}{$\begin{array}{l}\text { Lenguaje verbal y lenguaje } \\
\text { escrito }^{10,19} \\
\text { Lenguaje verbal en su idioma } \\
\text { primario coloquialmente de for- } \\
\text { ma clara y sencilla }{ }^{3} \text { con dicción } \\
\text { lenta para presentar los materia- } \\
\text { les, manteniendo contacto visual } \\
\text { de frente, cara a cara sin nada } \\
\text { que cubra el rostro, hablar len- } \\
\text { tamente para mejorar la articu- } \\
\text { lación de las palabras. }{ }^{11}\end{array}$} & $\begin{array}{l}\text { Verbal (Idioma español, } \\
\text { portugués o inglés) }\end{array}$ & $\begin{array}{l}\text { No toda la población de personas con deficiencias auditivas } \\
\text { está familiarizado con el lenguaje verbal } \\
\text { (español, portugués o inglés). } \\
\text { Dependiendo su edad y desarrollo es el grado de comprensión } \\
\text { sobre el idioma. } \\
\text { Ya que el vocabulario y el conocimiento de la lengua } \\
\text { se adquieren con el paso de los años y con la interacción } \\
\text { con el medio circundante. }{ }^{16} \\
\text { En personas con deficiencia auditiva congénita } \\
\text { es más difícil la comprensión de un lenguaje verbal } \\
\text { Genera miedo y estrés en ambas partes, al desconocer } \\
\text { la forma de establecer comunicación }{ }^{12}\end{array}$ \\
\hline & No verbal (Lenguaje escrito) & $\begin{array}{l}\text { El personal de salud no escribe legiblemente de la misma } \\
\text { forma las personas con deficiencias auditivas desconocen } \\
\text { los términos utilizados } \\
\text { Las indicaciones no son claras. }\end{array}$ \\
\hline
\end{tabular}




\begin{tabular}{|c|c|c|}
\hline $\begin{array}{l}\text { - Uso de familiares como } \\
\text { interprete. }{ }^{20} \\
\text { - Es el uso de personas } \\
\text { próximas, cercanas } \\
\text { o allegadas que conocen } \\
\text { bien a la persona cuvo }\end{array}$ & $\begin{array}{l}\text { Verbal (Idioma español, } \\
\text { portugués o inglés) }\end{array}$ & $\begin{array}{l}\text { La presencia del familiar en consulta hace que el derecho de las } \\
\text { personas a la confidencialidad médica se pierda. } \\
\text { Los familiares desconocen la semiología médica. } \\
\mathrm{Al} \text { interpretar el familiar, debido al lazo sentimental que compar- } \\
\text { ten pierde objetividad, ya que tienden a omitir aspectos impor- } \\
\text { tantes para el diagnóstico médico como mecanismo de protec- } \\
\text { ción a su familiar. } \\
\text { El paciente experimenta enojo y frustración debido al aislamien- } \\
\text { to que produce la triada personal de salud-familiar-paciente }{ }^{10}\end{array}$ \\
\hline $\begin{array}{l}\text { estado de salud se va } \\
\text { evaluar. Cuando el } \\
\text { individuo tiene menos } \\
\text { capacidad de comunicar } \\
\text { sus sentimientos y } \\
\text { opiniones o entender el } \\
\text { lenguaje verbal. } .^{22} \\
\text { - El familiar ayuda al } \\
\text { personal de salud a } \\
\text { comprender las señas, } \\
\text { de igual forma interpreta } \\
\text { los movimientos y facies } \\
\text { de su familiar con } \\
\text { deficiencia auditiva }\end{array}$ & No verbal (Lenguaje de señas) & $\begin{array}{l}\text { Hacen una traducción errónea del mensaje médico al desconocer } \\
\text { la semiología médica. } \\
\text { No hay una traducción eficaz familiar al personal de salud. }\end{array}$ \\
\hline \multirow[t]{2}{*}{$\begin{array}{l}\text { Lectura labial y facial }{ }^{16} \\
\text { Consiste en identificar } \\
\text { la articulación de las palabras } \\
\text { y fonemas de las personas } \\
\text { oyentes. }\end{array}$} & $\begin{array}{l}\text { Verbal (Idioma español, } \\
\text { portugués o inglés) }\end{array}$ & $\begin{array}{l}\text { - Una persona calificada solo puede comprender entre } \\
\text { un } 30 \text { y } 40 \% \text { de los sonidos verbales al ver los labios } \\
\text { de los oyentes. }{ }^{20} \\
\text { - Las personas desconocen la semiología médica. } \\
\text { - Mantener el contacto visual (cara a cara). Él personal de } \\
\text { salud comúnmente no mantiene el contacto o usa cubre } \\
\text { bocas. } \\
\text { - Es necesario saber lenguaje verbal (vocales, consonantes, } \\
\text { gramática etc.) saber interpretarlo (existen varianzas de } \\
\text { acuerdo al contexto de la persona sorda) } \\
\text { - Es una habilidad que la mayoría de las personas con } \\
\text { deficiencias auditivas congénitas no la pueden adquirir ya } \\
\text { que muchos fonemas del idioma se producen de forma } \\
\text { idéntica en los labios por ejemplo la F- V-T, D-K, G-B-P y } \\
\text { M representan casi la mitad de las consonantes. } \\
\text { - Los lectores labiales también deben saber identificar dónde } \\
\text { termina una palabra y donde comienza la siguiente. } \\
\text { - Las indicaciones no son entendidas por todos al utilizar el } \\
\text { lenguaje verbal ya que la dicción es muy rápida. }\end{array}$ \\
\hline & $\begin{array}{l}\text { No verbal (Gestos, Expresiones } \\
\text { faciales, Mirada intencional) }\end{array}$ & $\begin{array}{l}\text { - Debido a la carga de trabajo no cuentan con el tiempo } \\
\text { suficiente para observar detenidamente a sus pacientes. }{ }^{13} \\
\text { - La dicción de las personas es muy rápida por lo cual no } \\
\text { dan tiempo a la persona sorda para poder comprender las } \\
\text { palabras. }\end{array}$ \\
\hline
\end{tabular}




\begin{tabular}{|c|c|c|}
\hline 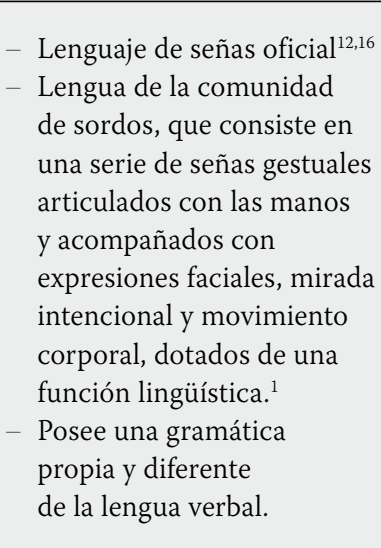 & $\begin{array}{l}\text { No verbal (Gestos, Movimien- } \\
\text { tos de las manos, expresiones } \\
\text { faciales, mirada intencional, } \\
\text { movimientos corporales) }\end{array}$ & $\begin{array}{l}\text { - Es importante mantener el contacto visual (cara a cara). } \\
\text { El personal de salud comúnmente no mantiene el contacto } \\
\text { o usa cubre bocas } \\
\text { - Es necesario saber lenguaje de señas, saber interpretarlo } \\
\text { (existen varianzas de acuerdo al contexto de la persona } \\
\text { sorda) } \\
\text { - Los profesionales de la salud no tienen formación en } \\
\text { lenguaje de señas. } \\
\text { - No conocen los gestos establecidos para dar indicaciones lo } \\
\text { que puede provocar dispersión de los participantes } \\
\text { - Las indicaciones no son entendidas por todos al utilizar el } \\
\text { lenguaje verbal } \\
\text { - Debido a la carga de trabajo no cuentan con el tiempo } \\
\text { suficiente para observar detenidamente a sus pacientes. }{ }^{13}\end{array}$ \\
\hline $\begin{array}{l}\text { - Uso de intérpretes } \\
\text { oficiales. }{ }^{20} \\
\text { - Estos deben de tener } \\
\text { experiencia en el manejo } \\
\text { de la terminología médica y } \\
\text { en la interpretación de una } \\
\text { forma sencilla y entendible } \\
\text { al lenguaje de señas, sin } \\
\text { salir del contexto medico. }{ }^{18} \\
\text { - } \text { La presencia del intérprete } \\
\text { debe estar mediada } \\
\text { bajo el derecho de } \\
\text { confidencialidad y no } \\
\text { emisión de juicios. }{ }^{24} \\
\text { - Se debe de explicar al } \\
\text { paciente la presencia } \\
\text { del intérprete y sobre }\end{array}$ & Verbal & $\begin{array}{l}\text { - La comunicación puede fallar debido al estrés que presenta } \\
\text { la persona con deficiencia auditiva debido a su estancia } \\
\text { hospitalaria. Así mismo se puede generar sentimientos } \\
\text { de enojo y frustración debido al aislamiento que genera la } \\
\text { conversación Interprete-profesional de salud. } \\
\text { - Una modalidad de los intérpretes oficiales es el uso de la } \\
\text { video conferencia y video llamada pero ambos requieren } \\
\text { de la disponibilidad de equipo y de personal especializado } \\
\text { para establecer y manejar el equipo (pantalla, video cámara, } \\
\text { computadora, internet, micrófonos etc.) } \\
\text { - Pueden provocar dispersión de los participantes. } \\
\text { - Las indicaciones no son entendidas por todos al utilizar el } \\
\text { lenguaje verbal. } \\
\text { - Su uso dependerá de la infraestructura de los hospitales. } \\
\text { - Son pocos los intérpretes oficiales. }\end{array}$ \\
\hline $\begin{array}{l}\text { todo los aspectos de la } \\
\text { consulta, pasos a seguir } \\
\text { y procedimientos; es } \\
\text { recomendable hacerlo } \\
\text { también en forma escrita } \\
\text { De esta forma se les estará } \\
\text { cubriendo su derecho } \\
\text { a recibir asistencia } \\
\text { lingüística. }{ }^{18} \\
\text { - Lo más importante es } \\
\text { confirmar que el paciente } \\
\text { esté entendiendo la } \\
\text { información e indicaciones } \\
\text { de diagnóstico, cuidado } \\
\text { y tratamiento. }\end{array}$ & $\begin{array}{l}\text { No verbal } \\
\text { (Lenguaje de señas oficial) }\end{array}$ & $\begin{array}{l}\text { - El uso de intérprete no siempre está disponible en las } \\
\text { instituciones de salud. } \\
\text { - Su traducción no siempre es la certera. } \\
\text { - Es necesario practicar antes el discurso para cotejar con las } \\
\text { presentadoras si es el mensaje correcto. } \\
\text { - Los intérpretes oficiales deben contar con experiencia en } \\
\text { lenguaje médico. }\end{array}$ \\
\hline
\end{tabular}

\section{Conclusiones}

La comunicación durante el cuidado de personas con alguna deficiencia auditiva parece no ser una prioridad importante por parte del gremio de enfermería dentro de nuestro país, pues se observa poco material de lectura documentado en comparación con otros países que han incursionado no solo en estrategias que garanticen la comunicación sino también en material didáctico y programas terapéuticos elaborados específicamente por enfermeras para garantizar la satisfacción de las necesidad de salud de sus pacientes.
Esta revisión permite concluir que la estrategia más exitosa para establecer comunicación con personas con deficiencias auditivas durante el cuidado es la utilización del lenguaje de señas; ya que éste es el lenguaje primario de esta población, su dominio permite 
conservar el derecho de confidencialidad enfermera-paciente, disminuye el estrés que provoca la presencia de terceros durante el cuidado y de acuerdo con lo estipulado con la ley se garantiza la inclusión plena y satisfactoria a los servicios de salud.

Por lo tanto se hace necesario que el personal de enfermería tenga conocimientos básicos del lenguaje de señas; esto permitirá la valoración de los procesos de enfermería y la elaboración de nuevas estrategias como materiales visuales que indiquen preguntas sencillas y directas acerca de las personas y sus necesidades.

También se hace explicita la necesidad de la enseñanza de diversas técnicas de comunicación y de otros lenguajes como el de los signos, desde la formación académica y la práctica laboral conforme las características de la población ya que ésta demanda diferentes formas de comunicación no verbal (en este caso), lo que permitirá ofrecer un cuidado con calidad.

Una reflexión obligada es cómo el personal de la salud pierde habilidad, debido a la monotonía y a la carga laboral, en establecer contacto directo con los pacientes, lo que tiene como resultado dar poca atención o que pasen desapercibidos movimientos corporales, faciales, labiales y miradas. Es necesario por tanto, innovación constante en este ámbito, sobre todo debido a que el éxito en el uso del lenguaje de signos requiere el contacto constante cara a cara entre el profesional de salud y la persona con deficiencias auditivas, se requiere además tiempo y dedicación para su aprendizaje y desarrollo; de no realizarse seguirá siendo una ba- rrera más para la comunicación. En cambio, su dominio se verá reflejado en el establecimiento de lazos de confianza entre la enfermera y la persona con deficiencias auditivas, facilitando la obtención de datos reales para la formación de su historial que ayuden a su pronto diagnóstico y atención oportuna. Esto favorecerá el desarrollo del lenguaje de signos propio del sector salud que ayude al entendimiento de la persona con deficiencias auditivas de su propia condición de salud.

El uso de intérpretes oficiales como estrategia de comunicación es exitoso siempre y cuando se cuente con los recursos económicos, disponibilidad hospitalaria y con experiencia dentro del sector salud. Su uso es no exitoso cuando las personas con deficiencias auditivas no están familiarizadas con su presencia lo que provoca omisión y tensión ante la triada enfermera-paciente-interprete.

Algo que llama la atención es que el uso de familiares como intérpretes resulta no exitoso para la situación de necesidad de salud, varios estudios reportan que la información proporcionada por la persona con deficiencias auditivas no es confiable debido al lazo sentimental que se comparte y viceversa, el que funge como traductor tiende a la mala traducción ante situaciones críticas de salud, con el propósito de proteger a su familiar, también el desconocimiento de la semiología médica contribuye al desvio del diagnóstico, con lo que los costos y la estancia hospitalaria se pueden ver prolongados generando a su vez malas experiencias que provocan renuencia por parte de la persona con deficiencias auditivas hacia el personal de salud.
Es importante señalar que la decisión de elección de estrategias exitosas de comunicación se verá influenciada directamente por la condición de la persona con deficiencias auditivas y el personal de salud se debe ajustar a su propia forma de comunicación de acuerdo a las necesidades de su paciente.

El personal de enfermería no debe escatimar en el uso de las nuevas tecnologías como el internet, que ofrece materiales muy accesibles para la enseñanza de temas de la salud e indicaciones para el cuidado; de la misma forma el experimentar en la creación de nuevos materiales con esta herramienta.

\section{Referencias Bibliográficas}

1 SEGOB. Ley General para la Inclusión de las Personas con Discapacidad en México [Internet]. Censo de Diario Oficial de la Federación; 30 Mayo 2011 [consulta 30 Enero 2012]. Disponible en: http://bit.ly/ j7jgda

2 Zacaula F, et-al. Lectura y redacción de textos. México: Santillana; 1998. pp. 14.

3 Andrade-Pereira PC, De CarvaLhoFortes PA. Communication and Information Barriers to Health Assistance for Deaf Patinets. American Annnals of the Deaf [Internet] 2010 [Consulta3 Febrero 2012]; 155(1): [31-37]. Disponible: http:// bit.ly/WrqtI3

4 Otero Martínez H. Hacia una comunicación efectiva y humanista en ámbitos de salud. Revista Habanera de Ciencias Médicas[Internet]. 2008 [Consulta 07 mayo 2012] Ene.-Mar 7(1). Disponible en:http://bit.ly/13CHP75

5 Barbosa-Alves M, Arimatéa-Oliveira M, Machado-Siqueira K, AlvesDamas KC, Aparecida do Prado 
M. Língua brasileira de sinais:um desafio para a assistência de enfermagem/ Brazilian language of signals: a challenge for nursing assistance, Rev. Enferm. UERJ [Internet]. 2003 [consulta 6 Septiembre 2011]; 11 (3): [247-241]. Disponible en: http://bit.ly/ZiM6GR

6 INEGI. Discapacidad en México. México: 2010 [consulta 30 Enero 2012]. Disponible en: http://bit.ly/ dVNVkl

7 Harvey MA. Shielding yourself the perils of empathy: The case of sign Language interpreters. J. Deaf Stud. Deaf Educ. [Internet]. 2003 [consulta 6 Septiembre 2011]; 8 (2): [207-213]. Disponible en: http://bit.ly/1061rzz

8 Méndez-Blanco MC; Ortiz-López E; Venegas-Vindas A. Estrategias de comunicación para el personal de Enfermería que atiende personas sordas. Rev. Enfermería Actual en Costa Rica [On line].2011 [consulta 07 Diciembre 2011] Oct.-Mar 21(1). Disponible en:http://bit.ly/ XSwLeQ

9 Lieu CC, Sadler GR, Fullerton JT, Stohhlmann PD. Commnuncation strategies for nurses interacting with deaf patients. Med Surg Nursing [On line].2007 [Consulta 3 Febrero 2012];16(4):[239-245] Disponible en: http://1.usa.gov/ Ypu5HH

10 Alves-Cardoso AH; Gomes-Rodrigues K, Bachion MM. Perception of persons with severe or profound deafness about the communication process during health care. Rev Latino-am Enfermagem [On line] 2006 Jul-Ago [Consulta 24 de Octubre 2011]; 14(4): [553-60]. Disponible en: http://bit.ly/15u1x3d

11 Da Silva-Correa C, Pereira L, Da Silva-Barreto L, Celestino-Priscilla P, Magalhães-André K. El des- pertar del enfermero en relación a los pacientes con pérdida de la audición. Rev. De pesq.: cuidado é fundamental [Online]. $2010 \mathrm{Abr} /$ Jun [consulta 13 de septiembre 2011]; 2(2):[758-769]. Disponible en: http://bit.ly/xwxo6K

12 Chaviero N, Porto-Celeno C, Alves-

Barbosa $\mathrm{M}$. The relation between deaf patients and the doctor. Rev. Bras. Otorrinolaringol [On line]. 2009 Ene/Feb [consulta 6 Septiembre 2011]; 75(1): [147-150]. Disponible en: http://bit.ly/YaTiCU

13 Gomes V, Correa M, Manfrin R, De Sosa JR. Vivencia del enfermero al cuidar sordos y/o portadores de deficiencia auditiva. Enferm Global -Esp-[On line]. 2009 oct. 2(17). Disponible en: http://bit.ly/ Z7qpM7

14 FinkeHE, Light J, Kitko L. A systematic review of the effectiveness of nurse communication with patients with complex communication needs with a focus on the use of augmentative and alternative communication J Clin Nurs. 2008 Aug;17(16):2102-15. Disponible en: http://bit.ly/wLDoIT

15 Rodríguez Sánchez BA. Proceso Enfermero. 2a ed. México: Cuellar;2000.p.35-49.

16 Sousa RA, Pagliuca LMF.Saúde sexual e reprodutiva para surdos: apreciação de uma metodologia educativa. Acta Paul Enferm [Internet] 2003 [Consulta 1 Febrero 2012];16(1):[22-29]. Disponible en: http://bit.ly/WtvKij

17 Joint Commission on Accreditation of health care organizations. $\mathrm{Na}$ tional Standards on Culturally and Linguistically Appropriate Services (CLAS):Competencies Organization for the Cultural, Norm 14Th - Standard 7 [Internet] 2006 [Consulta 1 de Mayo 2012]; 155(1):
[231-37]. Disponible en: http://1. usa.gov/ef27El

18 Jones EG, Goldsmith M, Effken J, Button K, Crago M. Creating and testing a deaf-friendly, stopsmoking web site intervention. . AM ANN DEAF[Internet] 2010 [Consulta 1 Febrero 2012]155(1): [96-102]. Disponible en: http://1. usa.gov/YbVGgS

19 McAleer M. Communicating effectively with deaf patients. Nurs Stand 2006; 20(19):51-54.

20 Alves R, Freitag LM. Educación especial para personas sordas. Una experiencia en la orientación sobre ETS/SIDA. Enferm Integral [On line]. 2005 [Consulta 3 Febrero 2012]; Junio[6-8] Disponible en: http://bit.ly/10bN5xp

21 González Pérez M. Abre los ojos. Técnicas de relajación en personas con deficiencia auditiva. Rev Presencia [On line] 2008 ene-jun, [Consulta 24 octubre 2011] 4(7). Disponible en :http://bit.ly/13FaRTy

22 Verdugo-Alonso MA, Sainz- Modinos F, Gómez-Sánchez LE, GómezSantamaría S. Bases para el desarrollo de un modelo de evaluación para personas con discapacidad intelectual adultas que viven en servicios residenciales. Salamanca: Inico [On line] 2011 [Consulta 3 Febrero 2012]:[63-65] Disponible en: http://bit.ly/YbsHWc

23 Hines J. Communication problems of hearing-impaired patients. [On line] Nurs Stand. 2000, [Consulta 21 Febrero 2012];14(19):[33-37]. Disponible en: http://1.usa.gov/ YtLIXmm

24. Secretaría de Salud. Carta de los derechos generales de las pacientes y los pacientes. [On line]. 2001 [Consulta 3 Febrero 2012]:[115] Disponible en: http://bit. ly/12sj5yz 


\section{Enfermería Universitaria}

\section{Índice Acumulativo}

\section{Revista Enfermería Universitaria}

\section{Revista No 1• Año 9• Enero • Marzo 2012}

El reto de la calidad bibliográfica en la investigación en enfermería The challenge of quality literature in nursing research Editorial MSP Ma. Victoria Fernández García.

Satisfacción laboral del profesional de enfermería en cuatro instituciones de salud Job satisfaction in nursing staff of four health institutions Mtra. Margarita Hernández Zavala. Mtra. Alicia Hernández Cantoral; Mtra.

Inserción laboral, desarrollo profesional y desempeño institucional de las (os) egresadas (os) del Plan Único de Especialización en Enfermería de la ENEO-UNAM: una experiencia de doce años. Labor market integration, professional development, and institutional performance of the graduates from the unique plan of specialization in nursing of the eneounam: a 12 year experience.

Dra. Carmen L. Balseiro Almario, Mtra. Rosa A. Zárate Grajales,

Mtra. Reyna Matus Miranda, EEAC Cristina Balan Gleaves, Mtro. Federico Sacristán Ruíz, Mtra. Mercedes García Cardona y PSS. Adriana Pérez Ruíz.

Perfil sociodemográfico y de intereses profesionales de los estudiantes de licenciatura en enfermería Socio-demographic profile and professional interests of students of Bachelor's degree in nursing

María de Jesús de Valle Alonso, Imelda Elena Hernández López, Perla Martínez Aguilera, Sonia Yolanda Barrón Cabrera, Martha López Hernández, Martha Lilia Zúñiga Vargas

\section{Interacción enfermera-paciente y su repercusión} en el cuidado hospitalario. Parte I Nurse-patient interaction and its repercussion to hospital care. Part । Mtra. en S.P. María Cristina Müggenburg Rodríguez Vigil, Dra. en Psic. Angélica Riveros-Rosas.

\section{Soluciones de Humanización en salud} en la práctica diaria Humanization Solutions health in daily practice 